\title{
Investor Sentiment and Return Predictability in Chinese Fuel Oil Futures Markets*
}

\author{
Qian Zhao ${ }^{1}$, Jianping $\mathrm{Li}^{2, \Psi}$, and Shuping Wang ${ }^{3}$ \\ ${ }^{1}$ School of Economics, Renmin University of China, Beijing 100872, P.R. China \\ zqheropen@yahoo.com.cn \\ ${ }^{2}$ Institute of Policy \& Management, Chinese Academy of Sciences, Beijing 100080, China \\ ljpacasipm.ac.cn \\ ${ }^{3}$ The College of Economics and Business Administration, North China University of \\ Technology, Beijing 100041, P.R. China \\ wangsp1@ruc.edu.cn
}

\begin{abstract}
We investigate the relation between investor sentiment and market returns in Chinese Fuel Oil Futures Markets by Vector Autoregressions (VAR) model. The sample period is from 5 September 2005 until 31 December 2006. Studies using daily datum on sentiments of professional advisors and individual investors suggest that past market returns are an important determinant of sentiment. Our evidence supports that not individual but professional sentiment has predictive power for returns. Extreme levels of sentiment do not possess any superiority in returns predictability with the exception of the individual bottom sentiment. For 1-week, 2week and 4-week intervals, returns can weakly predict sentiment or changes. Individual sentiment severs as a contrary indicator of returns in the followed week, whereas we find no evidence for the other circumstance.
\end{abstract}

Keywords: Returns Predictability; Investor Sentiment; Vector Autoregressions.

\section{Introduction}

The sentiment-return relation is an important and extensively researched topic in the finance literature. Indirect( Market-based) [1], direct (survey-based) [2-4] or integrated measures $[5,6]$ of sentiment are popularly used in order to find out whether sentiment follow or precede the stock markets. Several studies have also examined the causality in the futures markets with similar measures and the conclusions are mixed.

Simon et al [7] find that sentiment measures are able to predict returns on futures. Wang [8] shows that in the S\&P 500 index futures market, large speculator sentiment is a price continuation indicator, whereas large hedger sentiment is a contrary indicator. Small trader sentiment can hardly forecast future market movements.

\footnotetext{
* This research has been partially supported by a grant from National Natural Science Foundation of China (\#70531040), and 973 Project (\#2004CB720103), Ministry of Science and Technology, China.

${ }^{\Psi}$ Corresponding author.
}

Y. Shi et al. (Eds.): ICCS 2007, Part III, LNCS 4489, pp. 972 979, 2007.

(C) Springer-Verlag Berlin Heidelberg 2007 
Moreover, extreme large trader sentiments and the combination of extreme large trader sentiments tend to provide more reliable forecasts. Chen et al [9] reveal that contrary sentiment indicators improve the forecasting accuracy and profits earning capability in S\&P 500 futures. However, Dwight et al [10] demonstrate that the sentiment index displays only a sporadic and marginal ability to predict returns across 28 U.S. futures markets, and in those instances the pattern is one of return continuation-not reversals.

This study researches the causality in Chinese Fuel Oil Futures Markets. The primary focus is on the following two issues. Firstly, we test whether sentiment cause returns as predicted by the noise trader literature or sentiment simply responds to market behavior. Secondly, we examine whether extreme sentiment measures are useful for forecasting returns. Lastly, for robustness, we also test the causality with longer intervals.

\section{Data and Sample Statistics}

To empirically test our hypotheses, we use the results of a survey conducted by Jianzheng Future Brokerage Co. Ltd to measure the sentiment on a daily basis. The corporation gathers the opinions of above ten analysts, which form the professional advisers group. It also polls a random sample of its members each day, at the size of over one thousand, which represents the individual investors group. The sample period is from 5 September 2005 until 31 December 2006 for a total of 302 observations. The Bearish Sentiment Index at time $t\left(B S I_{t}\right)$ is measured by the bull-bear spread, ${ }^{1}$ the percentage of the bullish less that of the bearish.

A continuous series of futures return is created to match the sentiment data. The return $\left(R_{t}\right)$ is measured as the percentage change in settlement prices $\left(P_{t}\right)$ of the contract which is three months before the delivery date using a roll-over strategy, $\ln \left(P_{t} / P_{t-\mathrm{k}}\right)$. The data comes from Shanghai Futures Exchange.

It is necessary to examine the simple summary statistics to fully understand the datum and to motivate the time-series approach used in the analysis. Table 1 presents summary statistics for the datum. The results indicate that the average return is negative but not statistically different from zero. Sentiment is quite volatile, with large standard deviations and extreme values. The professional BSI ranges between 0.6 and -0.8 in our sample, and the individual, between 0.9598 and -0.6856 . Individual investors are too optimistic with a mean sentiment level notably over a neutral value 0 (50-50), when compared with the zero-mean return. We conduct stationary tests in order to avoid spurious regressions. According to ADF test three series are all stationary. The last column of Table 1 displays the contemporaneous correlation coefficient between returns and sentiment: 0.56 ( significantly positive at the $1 \%$ level with two-tailed $t$-test) for the professional and -0.05 ( not significantly) for the individual. But correlation is not equivalent to causality for the reason that opinions collected may be affected by prices during the day, which may produce the fictitious causality.

${ }^{1}$ Some other measures are tested in the paper, such as the ratio of the proportion of bearish investors to the whole investors. Results are omitted for parsimony since they are resemble. 
Table 1. Summary statistics of the sample datum

\begin{tabular}{llllllllll}
\hline & Mean & Max & Min & S.D & Skew & Kurto & J-B & ADF & Corr. \\
\hline BSIA & -2.28 & 60 & -80 & 23.30 & 0.02 & 4.07 & $14.39 * * *$ & $-11.44 * * *$ & 0.56 \\
BSIB & 40.06 & 95.98 & -68.6 & 34.59 & -0.43 & 2.64 & $10.83 * * *$ & $-2.13 * *$ & -0.05 \\
R & -0.02 & 4.02 & -5.03 & 1.47 & -0.46 & 3.70 & $16.77 * * *$ & $-17.45 * * *$ & - \\
\hline
\end{tabular}

Remark. Variables are professional sentiment (BSIA), individual sentiment (BSIB) and returns. $* * *, * * *$ denote significance at the $10,5,1 \%$ levels, respectively.

\section{Methodology and Results}

\subsection{Vector Autoregressions Model (VAR)}

In order to see how sentiment and market returns interact and identify the (statistical) causality between sentiment and the market, we use a set of VAR models, ${ }^{2}$ where Granger causality tests and impulse response functions are developed from.

The general model is

$$
\begin{aligned}
B S I_{t} & =c+\sum_{i=1}^{p} a_{i} B S I_{t-i}+\sum_{j=1}^{q} \mathrm{~b}_{\mathrm{j}} R_{t-j}+\varepsilon_{t} \\
R_{t} & =k+\sum_{i=1}^{m} \alpha_{i} R_{t-i}+\sum_{j=1}^{n} \beta_{j} B S I_{t-j}+\eta_{t}
\end{aligned}
$$

\subsubsection{Granger Causality Tests}

The bivariate Granger causality tests examine whether the lags of one variable enter the equation to determine the dependent variable, assuming that the two series ( $B S I$, and $R_{t}$ ) are covariance stationary and error items $\varepsilon_{t}, \eta_{t}$ i. i. $d$. white noise errors. ${ }^{3}$

A significant slope coefficient of equation (1) suggests that returns can predict sentiment. In equation (2) a significant and positive slope coefficient shows that the sentiment is a straight buying or selling indicator, while a negative coefficient implies that the sentiment is a contrary indicator.

We estimate the models using both levels and changes $\left(\Delta B S I_{t}\right)$ in sentiment measures since it is not easy to determine which specification should reveal the primary effects of sentiment. For example, suppose investor sentiment decreases from very bullish to bullish. One might anticipate a positive return due to the still bullish

\footnotetext{
${ }^{2}$ Hedgers who are concerned about fundamental information tend to hold positions for longer horizons, whereas speculators likely adjust positions over shorter horizons in response to short-term information. In the survey most of the individual are speculators, which make it sound to test our hypothesis using VAR although with limit observations.

${ }^{3}$ This assumption is tested using White [11] standard errors correct for heteroskedasticity. A Lagrange multiplier test is used to verify that the residuals are serially uncorrelated. AIC, BIC and Likelihood ratio tests are used to choose the best lag length. The appropriate test for the parameter restrictions is a Wald Chi-squared test.
} 
sentiment, but on the other hand, since sentiment has decreased it is also possible for someone to expect a reduction in the return.

Table 2 reports the results from estimating the daily sample using VAR for both professional and individual sentiment levels. The blocks of rows indicate the contribution of each lagged independent variable. As the first block of rows shows professional sentiment is strongly positively related to its past levels but less related to returns ( significant only at the 5\% level with a 3-day lag). The next column reveals that professional sentiment strongly predict returns. Individual sentiment is strongly positively related to its past levels and lagged returns according to the third column. However, in the last column, there is no evidence that the individual sentiment will predict returns.

These results confirm that both professional advisers and individual speculators are strongly swayed by recent market performance. Lagged levels of sentiment and market returns explain substantial variation in professional sentiment as indicated by the high $\overline{\mathrm{R}}^{2}$ of 0.155 , and individual sentiment by 0.749 . Besides, individual sentiment can not predict returns; but professional sentiment is a price-continuation indicator, probably due to their rational expectation of fundamental messages. We also find that individual sentiment is directed by professional sentiment (significant at the $10 \%$ level), but not vice versa.

Table 3 estimates the system using the changes in sentiments, showing that a change of either professional or individual sentiment is strongly related to its lagged levels and returns. Conversely, there is weak evidence that changes in the $\underline{\mathrm{R}}_{2}$ sentiment influence subsequent market returns, if any for the professional. The $\overline{\mathrm{R}}^{2}$ for each equation reveals that lagged sentiment changes and market returns explain roughly $30 \%$ of the professional sentiment and $8 \%$ of the individual sentiment, but less of the variability in the returns. Moreover, changes of the two sentiments have no causal relationship.

Table 2. Daily VAR-returns and professional-individual sentiment levels

\begin{tabular}{|c|c|c|c|c|c|c|c|}
\hline \multirow{2}{*}{$\begin{array}{l}\text { Independent } \\
\text { variable }\end{array}$} & \multirow[t]{2}{*}{ Lag } & \multicolumn{2}{|c|}{ Dependent variable } & \multirow{2}{*}{$\begin{array}{l}\text { Independent } \\
\text { variable }\end{array}$} & \multirow[t]{2}{*}{ Lag } & \multicolumn{2}{|c|}{ Dependent variable } \\
\hline & & BSIA & $\mathrm{R}$ & & & BSIB & $\mathrm{R}$ \\
\hline \multirow[t]{3}{*}{ BSIA } & 1 & $0.3341^{\text {***** }}$ & $0.0118^{* * *}$ & BSIB & 1 & $0.7248^{\text {***** }}$ & -0.0068 \\
\hline & 2 & -0.0264 & $-0.0162^{* * *}$ & & 2 & $0.1600^{* * * *}$ & 0.0050 \\
\hline & 3 & $0.2430^{* * *}$ & $00.0141^{* * *}$ & & & & \\
\hline sum impact & & $0.5508^{* * *}$ & -0.0828 & & & & -0.0019 \\
\hline \multirow[t]{3}{*}{$\mathrm{R}$} & 1 & -0.3990 & -0.0828 & $\mathrm{R}$ & 1 & $1.4180^{* *}$ & -0.0176 \\
\hline & 2 & 0.7616 & -0.0044 & & 2 & $1.4115^{* *}$ & -0.0948 \\
\hline & 3 & $-2.1907^{* *}$ & -0.1101 & & & & \\
\hline sum impact & & -1.8281 & -0.1973 & & & $2.8295^{* * *}$ & -0.1124 \\
\hline constant & & -1.580 & 0.0033 & & & 4.7823 & 0.0576 \\
\hline $\begin{array}{l}\text { Block } \\
\text { exogenity }\end{array}$ & & 5.356 & $19.110^{* * * *}$ & & & $8.447^{* *}$ & 2.155 \\
\hline$\overline{\mathrm{R}}^{2}$ & & 0.155 & 0.053 & & & 0.749 & 0.004 \\
\hline
\end{tabular}


In summary, this section reveals that market returns are a strong predictor of subsequent sentiment for both professional advisors and individual investors. In contrast, there is no evidence that individual sentiment is useful in predicting future returns over short horizons, whereas professional sentiment is a price indicator.

Table 3. Daily VAR-returns and professional-individual sentiment changes

\begin{tabular}{|c|c|c|c|c|c|c|c|}
\hline \multirow{2}{*}{$\begin{array}{l}\text { Independent } \\
\text { variable }\end{array}$} & \multirow[t]{2}{*}{ Lag } & \multicolumn{2}{|c|}{ Dependent variable } & \multirow{2}{*}{$\begin{array}{l}\text { Independent } \\
\text { variable }\end{array}$} & \multirow[t]{2}{*}{ Lag } & \multicolumn{2}{|c|}{ Dependent variable } \\
\hline & & $\Delta$ BSIA & $\mathrm{R}$ & & & $\Delta \mathrm{BSIB}$ & $\mathrm{R}$ \\
\hline \multirow[t]{3}{*}{$\Delta \mathrm{BSIA}$} & 1 & $-0.4891^{* * * * *}$ & $0.0093^{* * *}$ & \multirow[t]{5}{*}{$\Delta \mathrm{BSIB}$} & 1 & - & -0.0069 \\
\hline & 2 & $-0.3822^{* * *}$ & -0.0080 & & 2 & $\begin{array}{l}0.2452 \\
-0.1272^{\text {** }}\end{array}$ & -0.0048 \\
\hline & 3 & -0.0087 & $0.0067^{*}$ & & & & \\
\hline \multirow[t]{2}{*}{ sum impact } & & $-0.8799^{* * *}$ & 0.0081 & & & - & -0.0117 \\
\hline & & & & & & $0.3724^{* * * *}$ & \\
\hline \multirow[t]{3}{*}{$\mathrm{R}$} & 1 & $-2.1346^{* *}$ & -0.0443 & \multirow[t]{8}{*}{$\mathrm{R}$} & 1 & $1.4417^{* *}$ & -0.0201 \\
\hline & 2 & -1.0101 & -0.0013 & & 2 & $1.5394^{* *}$ & -0.0183 \\
\hline & 3 & $-4.1232^{* * * *}$ & -0.0970 & & & & \\
\hline sum impact & & $-7.2678^{* * *}$ & -0.1426 & & & $2.9810^{* * *}$ & -0.1107 \\
\hline constant & & -0.5121 & -0.0198 & & & 0.2043 & -0.0183 \\
\hline Block & & $0.0000^{* * *}$ & $0.0003^{* * * *}$ & & & $0.0100^{* * * *}$ & 0.2691 \\
\hline exogenity & & & & & & & \\
\hline$\overline{\mathrm{R}}^{2}$ & & 0.285 & 0.053 & & & 0.074 & 0.006 \\
\hline
\end{tabular}

Remark. Sum impact indicates the aggregate sign of causality of all lags of an explanatory variable, the null hypothesis that it equals zero is tested using a Chisquared test. Block exogenity reports the value of an F-test that the coefficients on all lags of all independent variables (other than own-lags) are jointly zero. Variables are changes of professional sentiment ( $\Delta$ BSIA) and individual sentiment ( $\Delta$ BSIB) and returns.

\subsubsection{Impulse Response Function}

An impulse response function investigates the response of one variable to one standard deviation change of another variable by using the moving average representation of the shocks for vector autoregression. Fig. 1 provides the results revealing the time path of the dynamic interaction patterns between sentiment of the professional and returns, where the figure of the individual is omitted. It can be found that a shock in daily returns causes the greatest initial increase and then a steep decline in professional sentiment, whereas the individual sentiment responds much more slowly. Returns respond volatile to professional sentiment but insignificantly to individual sentiment. Furthermore, sentiment is strongly affected by its own lagged variable. On all accounts, the results are generally consistent with those obtained by Granger causality tests.

\subsection{Extreme Levels of Sentiment and Returns}

While the causality test results presented above do not indicate a consistent relationship between noise trader's sentiment and subsequent price movements, it 
Response to Cholesky One S.D. Innovations \pm 2 S.E.
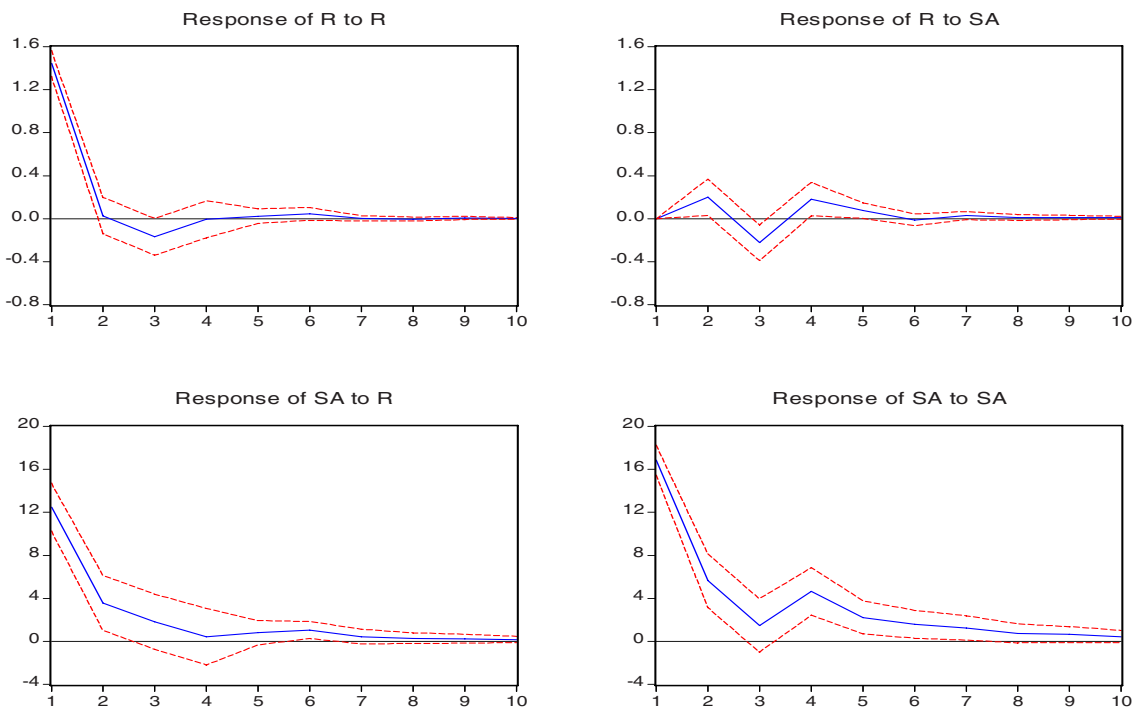

Fig. 1. Responses to Cholesky Innovations between professional sentiment and returns

may be possible that a relationship exists, but only at extreme levels of sentiment. The hypothesis is tested by forming two groups based on sentiment: the extremely bullish group (top 20\%) and the extremely bearish group (bottom 20\%). Results are shown in Table 4 . The slope coefficients are insignificant at the $10 \%$ level by $t$ test, with the exception of the individual bottom $20 \%$ sentiment since the equation is well fitted by $t$ and $F$ tests. This suggests that individual bottom sentiment severs as a contrary indicator of returns, and that other extreme sentiment levels could hardly predict returns.

Table 4. Regression results of returns on extreme levels of sentiment

\begin{tabular}{clllllll}
\hline $\begin{array}{l}\text { Dependent } \\
\text { variable }\end{array}$ & Group & Intercept & $\begin{array}{l}\text { Slope } \\
\text { coefficient }\end{array}$ & t value & $\mathrm{R}^{2}$ & Adj. $\mathrm{R}^{2}$ & $\mathrm{~F}$ value \\
\hline \multirow{2}{*}{ BSIA } & Top & 0.374 & -0.003 & -0.211 & 0.001 & -0.021 & 0.045 \\
& bottom & 0.659 & 0.020 & 1.563 & 0.037 & 0.022 & 2.442 \\
& Total & 0.123 & 0.005 & 1.343 & 0.016 & 0.007 & 1.804 \\
& Top & 2.441 & -0.029 & -0.633 & 0.009 & -0.013 & 0.400 \\
BSIB & bottom & -0.007 & -0.018 & $-2.295^{* * *}$ & 0.076 & 0.062 & 5.268 \\
& Total & 0.107 & -0.003 & -1.369 & 0.017 & 0.008 & 1.873 \\
\hline
\end{tabular}

\subsection{Robustness}

We repeat the analysis using the data for 1-week, 2-week and 4-week intervals (Monday-Monday), because it is possible that people's perception of risk will be changed over a longer interval than one day, and because it take some time for the 
investing decisions to be carried out. Table 5 shows that professional sentiment and changes is respectively related to lag returns for the 1-week and 2-week horizon, both significant at the $10 \%$ level, however, individual sentiment is not affected by returns for any of the tested horizon. Table 6 shows that future returns is negatively related to changes of individual sentiment for the 1-week horizon (strongly significant at the $1 \%$ level) and the latter explains $16 \%$ of the returns, whereas the coefficients in the other circumstances are insignificant.

Table 5. The regression results of professional and individual sentiment on returns

\begin{tabular}{llllrrl}
\hline Interval & Parameter & BSIA & $\Delta$ BSIA & BSIB & $\Delta$ BSIB & Observations \\
\hline \multirow{2}{*}{ 1-week } & Coefficient. & 1.144 & $-2.205^{*}$ & 0.484 & -0.376 & \multirow{2}{*}{60} \\
& Adj.R ${ }^{2}$ & 0.008 & 0.068 & -0.015 & -0.015 & \\
\multirow{2}{*}{ 2-week } & Coefficient. & $1.651^{*}$ & -0.990 & 0.336 & -0.807 & \multirow{2}{*}{32} \\
& Adj.R ${ }^{2}$ & 0.086 & -0.012 & -0.033 & -0.023 & \\
\multirow{2}{*}{ 4-week } & Coefficient. & -0.513 & -2.687 & 0.390 & -0.716 & \multirow{2}{*}{16} \\
& Adj.R ${ }^{2}$ & -0.066 & 0.127 & -0.085 & -0.079 & \\
\hline
\end{tabular}

Table 6. The regression results of returns on professional and individual sentiment

\begin{tabular}{|c|c|c|c|c|c|c|}
\hline Interval & Parameter & BSIA & $\Delta$ BSIA & BSIB & $\Delta \mathrm{BSIB}$ & Observations \\
\hline \multirow{2}{*}{ 1-week } & Coefficient & -0.008 & 0.0003 & -0.015 & $-0.054 * * *$ & \multirow{2}{*}{60} \\
\hline & Adj. $R^{2}$ & -0.013 & -0.018 & 0.0006 & 0.160 & \\
\hline \multirow{2}{*}{ 2-week } & Coefficient & -0.0006 & -0.015 & 0.013 & -0.035 & \multirow{2}{*}{32} \\
\hline & Adj. $R^{2}$ & -0.034 & -0.027 & -0.027 & 0.030 & \\
\hline \multirow{2}{*}{ 4-week } & Coefficient & -0.031 & -0.025 & 0.076 & 0.064 & \multirow{2}{*}{16} \\
\hline & Adj. $R^{2}$ & -0.070 & -0.065 & 0.085 & 0.125 & \\
\hline
\end{tabular}

Remark. Test statistics for individual coefficients is computed using White (1980)

heteroskedasticity consistent standard errors. $* * * * *$, and $*$ denote significance at the 1,5 , and $10 \%$ levels, respectively.

\section{Summary and Conclusions}

In summary, we have demonstrated that survey-measuring investor sentiments are related to market returns. We find little evidence of short-run (1-day interval) predictability in returns for individual sentiment, but strong evidence for professional sentiment. Neither professional nor individual extreme sentiment could predict returns, with the exception of the individual bottom $20 \%$ sentiment. For 1-week, 2 week and 4-week intervals, sentiment and changes is weakly related to lag returns, which may be interpreted by the thing that individual investors make their decisions on short time market information. Individual sentiment can explains $16 \%$ of the returns a week later and it severs as a contrary indicator of returns, whereas the coefficients in the other circumstances are insignificant. We also reveal that professional sentiment is a predictor of individual sentiment, but not vice versa. Since the datum used in our tests are short, the findings might be improved by including more observations. 
More work remains to be done in studying the determinants of investor sentiment and the value of forecast based on sentiment of different types of traders (arbitragers and speculators) in the futures markets. Some other sentiment measures may be constructed to test the robustness of our conclusions.

\section{References}

1. Parkinson, M. The extreme value method for estimating the variance of the rate of return. Journal of Business, 1992, (53): 61-65.

2. M.E. Solt, M. Statman, How useful is the sentiment index? Financial Analysts Journal, 44 (1988), 45-55.

3. K.L. Fisher, M. Statman, Investor sentiment and stock returns. Financial Analysts Journal, 56 (2000), 16-23.

4. W. B. Gregory, T. C. Michael, Investor sentiment and asset valuation. The Journal of Business, 78 (2005), 405-440. monthly daily

5. G. W. Brown, M. T. Cliff, Investor sentiment and the near-term stock market. Journal of Empirical Finance, 11 (2004), 1-27.

6. Y. Wang, K. Aneel, J. T. Stephen, The relationships between sentiment, returns and volatility. International Journal of Forecasting, 22 (2006), 109-123.

7. D. P. Simon, R. A. Wiggins, S\&P futures returns and contrary sentiment indicators. Journal of Futures Markets, 21 (2001), 447-462.

8. C. Wang, Investor sentiment and return predictability in agricultural futures markets. Journal of Futures Markets, 21 (2001), 929-952.

9. A. Chen, Y. Chang, Using extended classifier system to forecast S\&P futures based on contrary sentiment indicators. Evolutionary Computation, 3 (2005), 2084- 2090.

10. R. S. Dwight, H. I. Scott, M. L. Raymond, The theory of contrary opinion: A test using sentiment indexes in futures markets. Journal of Agribusiness, 21 (2003), 39-64.

11. H. White, A heteroskedasticity-consistent covariance matrix estimator and a direct test for heteroskedasticity. Econometrica, 48 (1980), 817-838. 